\title{
Molecular Approach to Generate Cu(II) Sites on Silica for the Selective Partial Oxidation of Methane
}

\author{
Jordan Meyet ${ }^{\S a}$, Mark A. Newton ${ }^{a}$, Jeroen A. van Bokhovenªb, and Christophe Copéret ${ }^{\star a}$ \\ §SCS-Metrohm Award for the Best Oral Presentation in Inorganic Chemistry
}

\begin{abstract}
The selective partial oxidation of methane to methanol remains a great challenge in the field of catalysis. Cu-exchanged zeolites are promising materials, directly and selectively converting methane to methanol with high yield under cyclic conditions. However, the economic viability of these aluminosilicate materials for potential industrial applications remains a challenge. Exploring copper supported on non-microporous oxide supports and rationalising the structure/reactivity relationships extends the scope of material investigation and opens new possibilities. Recently, copper on alumina was demonstrated to be active and selective for the partial oxidation of methane. This work aims to explore the formation of well-defined $\mathrm{Cu}(I)$ oxo species on silica via surface organometallic chemistry and examines their reactivity for the selective transformation of methane to methanol. Isolated $\mathrm{Cu}(I)$ sites were generated via grafting of a tailored molecular precursor. Activation under oxidative conditions and subsequent removal of organic moieties from the grafted copper centres led to the formation of small copper (II) oxide clusters, which are active in the partial oxidation of methane under mild conditions, albeit significantly less efficient than the corresponding isolated $\mathrm{Cu}(I)$ sites on alumina.
\end{abstract}

Keywords: Copper · Molecular approach · Oxide support $\cdot$ Partial oxidation of methane $\cdot$ Surface organometallic chemistry

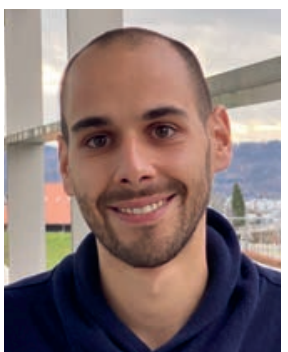

Jordan Meyet was awarded a Bachelor's degree with distinction in Chemistry at Heriot-Watt University in 2012. He pursued his education in France at CPE Lyon where after a gap year in industry (LANXESS The Netherlands) and a Master thesis in the group of Prof. Christophe Copéret at ETH Zürich, he graduated with a Master's degree in Inorganic Chemistry and an Engineering degree in Chemistry. He is currently a $\mathrm{PhD}$ student in the groups of Prof. Christophe Copéret and Prof. Jeroen A. van Bokhoven at the ETH Zürich, where his research focuses on the understanding of the active copper sites for the selective conversion of methane to methanol.

\section{Introduction}

The valorisation of methane, a major constituent of natural gas, has attracted much attention this past decade as a part of a potential energy transition from a petroleum-based economy. Conversion of methane to form more valuable commodity chemicals and liquid energy carriers, such as methanol, faces severe challenges due to the higher propensity of the desired products to further oxidize compared to methane. Extensive work has shown that $\mathrm{Cu}$-exchanged zeolites are capable of selectively facilitating this transformation, ${ }^{[1-4]}$ using molecular oxygen as a primary oxidant. These materials demonstrate high selectivity and high yields of methanol per copper when the reaction is performed under stepwise conditions (i.e. chemical looping). ${ }^{[5]}$ However, economic analysis of these materials shows severe challenges for their im- plementation in an industrial process. ${ }^{[6]}$ Major issues concern the optimisation of the stepwise process (temperature, pressure) and the possibility of performing this transformation catalytically and selectively. ${ }^{[7]}$ In addition, the price of zeolitic material is a barrier because of the low space-time yield of methanol, as calculated for several $\mathrm{Cu}$-exchanged materials. ${ }^{[6]}$ The ideal material would have a very high copper loading and with an inexpensive synthetic protocol, neither of which is the case for zeolite-based materials.

Despite intensive research on the step-wise methane to methanol conversion, only few studies have explored copper supported on non-zeolitic supports. ${ }^{[8-10]}$ Cheap and readily available oxides, such as silica and alumina, are attractive because they combine high surface area and the absence of microporosity, thereby minimizing diffusion limitations. To explore and better understand the reactivity of copper supported on non-microporous oxides, we prepared a well-defined molecular precursor on partially dehydroxylated silica via a surface organometallic chemistry (SOMC) approach. ${ }^{[11]}$ This methodology allows control of the copper speciation along with its density and dispersion on the support. ${ }^{[11-13]}$ We have previously demonstrated that this approach results in the formation of well-dispersed $\mathrm{Cu}$ (II) sites on alumina after thermal activation under synthetic air. These materials showed both activity and selectivity for the partial oxidation of methane to methanol, where monomeric $\mathrm{Cu}$ (II) sites with an $\mathrm{Si} / \mathrm{Al}$ environment were identified as reactive sites. ${ }^{[14]}$ Therefore, we decided to explore the possibility to generate isolated monomeric copper centres on silica, i.e. within a purely siliceous environment, and to study their reactivity towards the partial oxidation of methane. Here, we show that well-defined monomeric $\mathrm{Cu}$ (II) surface complexes 
can be formed on silica upon grafting. However, upon subsequent thermal treatment under oxidative conditions, while the organic moieties are fully removed, evidence for the aggregation of copper into small $\mathrm{Cu}$ (II) oxide clusters is found. This material activates methane under mild conditions to yield methoxy and formate surface species, but the productivity observed per $\mathrm{Cu}(0.027$ mol $\mathrm{CH}_{3} \mathrm{OH} . \mathrm{mol}^{-1} \mathrm{Cu}$ ) after aqueous extraction is significantly lower than previously reported for monomeric copper on alumina (0.11 mol CH $\mathrm{CH}_{3} \mathrm{OHol}{ }^{-1} \mathrm{Cu}$ ), suggesting the importance of the aluminium environment for the dispersion and formation of reactive $\mathrm{Cu}$ (II) centres.

\section{Results and Discussion}

We synthesized a mononuclear $\mathrm{Cu}(\mathrm{II})$ siloxide complex, $\left[\mathrm{Cu}\left(\mathrm{OSi}(\mathrm{OtBu})_{3}\right)_{2}(\mathrm{TMEDA})\right] \quad(\mathbf{1}$, tetramethylethylenediamine, TMEDA), which has previously been characterized using a combination of spectroscopic techniques: X-ray crystallography, electron paramagnetic resonance (EPR) and IR spectroscopy. ${ }^{[14]}$ Contacting a solution of $\mathbf{1}\left(0.32 \mathrm{mmol} . \mathrm{g}^{-1} \mathrm{SiO}_{2-700}\right)$ in benzene for $16 \mathrm{~h}$ with partially dehydroxylated silica $\left(\mathrm{SiO}_{2-700}, \mathrm{OH}\right.$ density $=$ $0.9 \mathrm{OH} . \mathrm{nm}^{-2}$ ) yields, after washing and drying, a deep blue powder (Fig. 1). Mass balance analysis of the released product $(0.21$ $\left.\mathrm{mmol} \mathrm{HOSi}(\mathrm{OtBu})_{3} \cdot \mathrm{g}^{-1} \mathrm{SiO}_{2-700}\right)$ and elemental analysis of the material $\left(1.35 \mathrm{wt} \% \mathrm{Cu}, 0.21 \mathrm{mmol}^{-1} \mathrm{SiO}_{2-70}\right)$ are consistent with the formation of $\left[(\equiv \mathrm{SiO}) \mathrm{Cu}\left(\mathrm{OSi}(\mathrm{OtBu})_{3}\right)(\mathrm{TMEDA})\right]\left(\mathbf{1} @ \mathrm{SiO}_{2-700}\right.$ $\left.0.6 \mathrm{Cu} . \mathrm{nm}^{-2}\right)$ surface species via grafting.

To gain understanding of the surface copper species formed upon the grafting, the materials were characterized using a combination of spectroscopic techniques and compared with the spectral features observed for the molecular $\mathrm{Cu}$ (II) siloxide complex (1). Grafting of $\mathbf{1}$ on $\mathrm{SiO}_{2-700}$ through protonolysis was evidenced using FTIR spectroscopy by the disappearance of isolated silanol band $\left(3747 \mathrm{~cm}^{-1}\right)$ and appearance of the $\mathrm{C}-\mathrm{H}$ stretching and bending modes of the siloxide ligand (Fig. 1). Moreover, the presence of the $\mathrm{N}-\mathrm{CH}_{3}$ stretching vibration at $2870 \mathrm{~cm}^{-1}$ confirmed the presence of TMEDA ligands on the surface, consistent with the mass balance analysis by ${ }^{1} \mathrm{H}$ NMR. The retention of the $\mathrm{Cu}$ (II) oxidation state upon grafting was confirmed by $\mathrm{Cu} \mathrm{K}$-edge $\mathrm{X}$-ray adsorption near edge spectroscopic (XANES), in contrast with the partial reduction of the $\mathrm{Cu}$ (II) sites observed when grafted on alumina.

The blue-coloured grafted and dried material $\left(1 @ \mathrm{SiO}_{2-700}\right)$ was further characterized by UV-vis and EPR spectroscopy; spectra were compared to those for the molecular complex (1). The optical spectrum shows two main features at $272 \mathrm{~nm}$ and $715 \mathrm{~nm}$ (Fig. 2a), assigned respectively to the ligand to metal charge transfer (LMCT) and d-d transition of distorted octahedral $\mathrm{Cu}(\mathrm{II})\left(\mathrm{d}^{9}\right)$. The supported material is characterized by an axial EPR signal $\left(g_{\|}>g_{\perp}>g_{e}\right)$, with a partially resolved hyperfine structure on the $g_{\|}$component (Fig. 2b). The broad signal prevents precise determination of the hyperfine interaction of the unpaired electron with the nuclear spin $(\mathrm{Cu}, \mathrm{I}=3 / 2)$; however, this can be attributed to either a magnetic interaction between the supported paramagnetic centres and/or a broad distribution of sites with slightly different geometric configurations. The absence of half-field transition $(\Delta \mathrm{Ms}=2)$, previously observed for dimeric copper supported on silica, ${ }^{[15]}$ suggests the absence of dimers on the surface and confirms the dispersion of the monomeric molecular complex on the surface. The anisotropy of the signal was observed at room temperature with identical features compared to the spectra recorded at $100 \mathrm{~K}$ (Fig. 2b), consistent with the formation of covalent interaction with the silica support.[16] Interestingly, the distribution of the EPR $g$ parameters reveals a $d_{x^{2}-y^{2}}$ ground state consistent with an elongated square pyramidal or elongated octahedral environment of the copper centre. This is in stark contrast with the parameters measured for the molecular complex (1), which displays a $\mathrm{d}_{z^{2}}$ ground state, indicating a complete change of copper coordination that was induced by grafting on the surface of silica. In conclusion, grafting the molecular complex (1) on partially dehydroxylated silica $\left(\mathrm{SiO}_{2-700}\right)$ allows the formation of well-dispersed $\mathrm{Cu}$ (II) complex species characterized by a change in the copper coordination environment and retention of the mononuclearity of the molecular precursor $\left(0.6 \mathrm{Cu} . \mathrm{nm}^{-2}\right)$.

Thermal treatment of the material at $350{ }^{\circ} \mathrm{C}$ under high vacuum $\left(10^{-5}\right.$ mbar $)$ resulted in the incomplete removal of organic

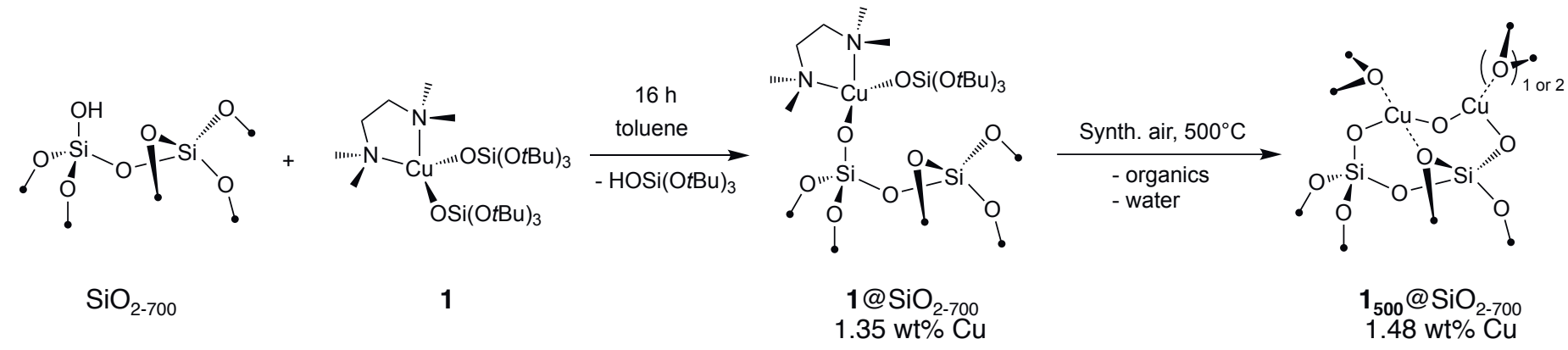

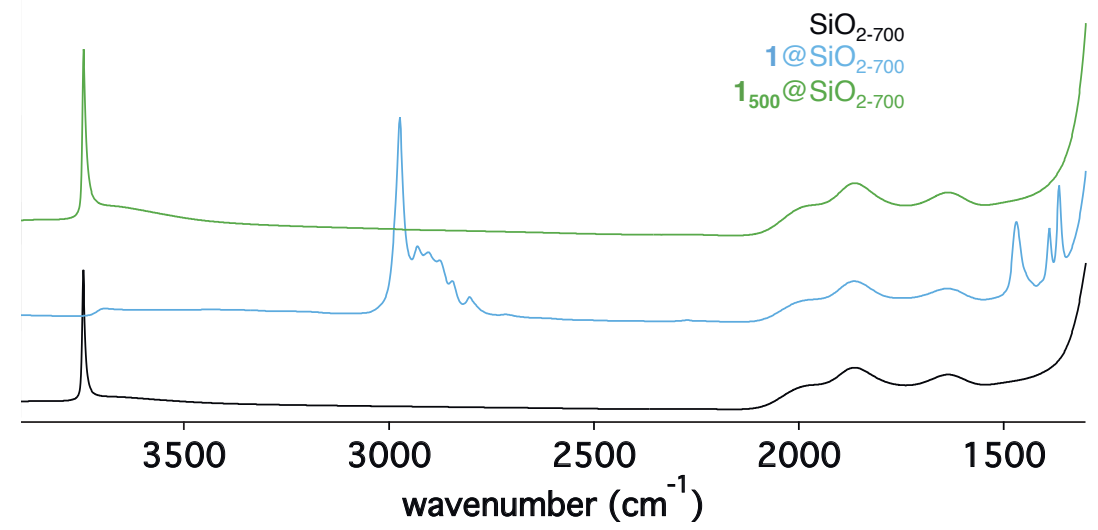

Fig. 1. (top) Schematic representation of the grafting and calcination of 1 on $\mathrm{SiO}_{2-700}$ and (bottom) the corresponding FT-IR spectra of the material at each step. 
moieties (i.e. - OtBu and TMEDA) and partial reduction of copper, as confirmed by carbon monoxide adsorption monitored by IR. However, a direct calcination/activation step (under flow of dry synthetic air) at $500{ }^{\circ} \mathrm{C}$ yields exclusively $\mathrm{Cu}$ (II) surface sites, as confirmed by $\mathrm{Cu} \mathrm{K}$-edge XANES. Applying thermal oxygen treatment to the grafted material $\left(\mathbf{1} @ \mathrm{SiO}_{2-700}\right)$ for $12 \mathrm{~h}$ leads to a green material $\left(\mathbf{1}_{\mathbf{5 0 0}} @ \mathrm{SiO}_{2-700}\right)$, which is free of organic ligands as evidenced by the absence of any $\mathrm{C}-\mathrm{H}$ stretching and bending bands in the IR (Fig. 1). Thermal transformation of the ligands is accompanied by the formation of water, resulting in the observed recovery of surface silanol groups upon calcination (Fig. 1). The thermally activated material was characterized and compared to the grafted species by employing similar spectroscopic techniques(a). The UV-vis spectrum of the calcined material $\mathbf{1}_{\mathbf{5 0 0}} @$

a)

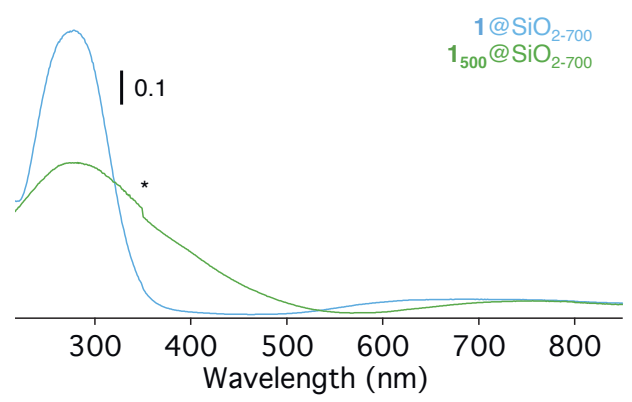

b)

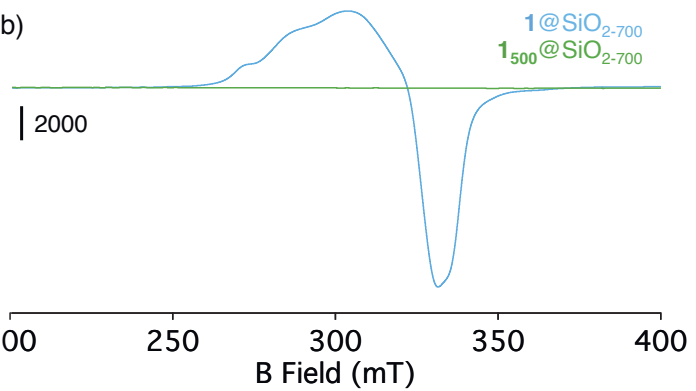

been investigated. $\mathbf{1}_{\mathbf{5 0 0}} @ \mathrm{SiO}_{2-700}$ was reacted with 6 bar of methane at $200{ }^{\circ} \mathrm{C}$ for $30 \mathrm{~min}$, and the resulting material was characterized by FTIR (Fig. 3). The IR spectrum after reaction shows the appearance of three new bands in the $\mathrm{C}-\mathrm{H}$ vibration area (3000$2800 \mathrm{~cm}^{-1}$ ). The two bands at 2962 and $2858 \mathrm{~cm}^{-1}$ are associated to the symmetric and antisymmetric $\mathrm{C}-\mathrm{H}$ stretching of surface methoxy species bound to the surface while the band at $2928 \mathrm{~cm}^{-1}$ was reported for monodentate formate species.

The surface species formed are strongly bound to the surface and require a hydrolysis step to recover the desired product. After water extraction, $6.2 \mu \mathrm{mol} . \mathrm{g}^{-1}$ of methanol was recovered, corresponding to a methanol yield of $0.027 \mathrm{~mol} \mathrm{CH} \mathrm{OH}_{3} \mathrm{~mol}^{-1} \mathrm{Cu}$. Although the methanol yield is relatively low, $\mathrm{Cu}(\mathrm{II})$ supported on silica is capable of activating methane. The next challenge is to

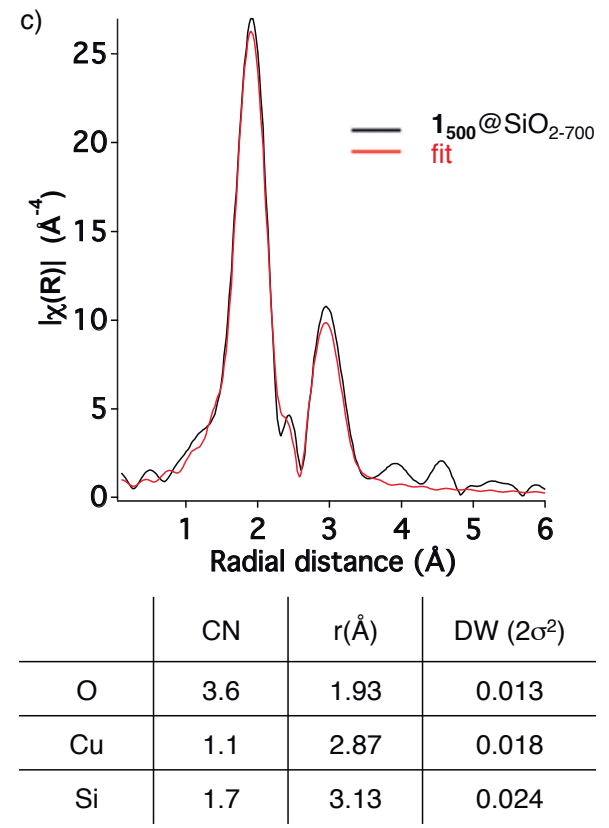

Fig. 2. (a) DRS spectra and (b) X-band EPR spectra at $100 \mathrm{~K}$ of the supported $\left(\mathbf{1}_{\mathrm{SSiO}} \mathrm{2}_{-700}\right)$ and thermally activated $\left(\mathbf{1}_{500} @ \mathrm{SiO}_{2-700}\right) \mathrm{material}_{\text {. }}$ (c) Fourier transform Cu K-edge EXAFS spectra and analysis of 1@SiO2-700.

$\mathrm{SiO}_{2-700}$ displays a slightly broader LMCT band at $283 \mathrm{~nm}$ and the d-d transition of the $\mathrm{Cu}$ (II) at $763 \mathrm{~nm}$ (Fig. 2a), red-shifted compared to the grafted material. These experimental features point to the formation of $\mathrm{Cu}$ (II) oxide clusters, in agreement with previous reports for $\mathrm{Cu}(\mathrm{II})$ supported on silica by impregnation method. ${ }^{[9,10]}$ The EPR spectrum of the calcined material shows no signal (Fig. 2b), in spite of the confirmed presence of $\mathrm{Cu}$ (II) species via XANES and UV-vis. The complete absence of signal is likely due to antiferromagnetic exchange interactions between the $\mathrm{Cu}$ (II) centres present in the copper oxide clusters, that result in EPR-silent diamagnetic species.

The thermally activated material was further analysed by $\mathrm{Cu}$ K-edge extended X-ray adsorption spectroscopy (EXAFS) (Fig. 2c). The Fourier transformed EXAFS spectrum exhibits only one major scattering in the first coordination shell, fitted to $3.6 \mathrm{O}$ at $1.93 \AA$. Additional scattering contributions at $2.87 \AA$ and $3.13 \AA$ can be fitted with the presence of $1.1 \mathrm{Cu}$ and $1.7 \mathrm{Si}$ in the second coordination sphere respectively. The absence of long-range scattering along with the low coordination number of copper in the second coordination sphere suggest the formation of dimeric $\mathrm{Cu}$ (II) species on the surface. However, the absence of half-field transition from EPR data and the absence of characteristic features for dimeric $\mathrm{Cu}$ (II)-oxo species by UV-vis implies the formation of highly dispersed $\mathrm{Cu}$ (II) oxide clusters on the silica surface.

The reactivity of this material with methane under mild conditions, along with the identities of the surface species formed, has

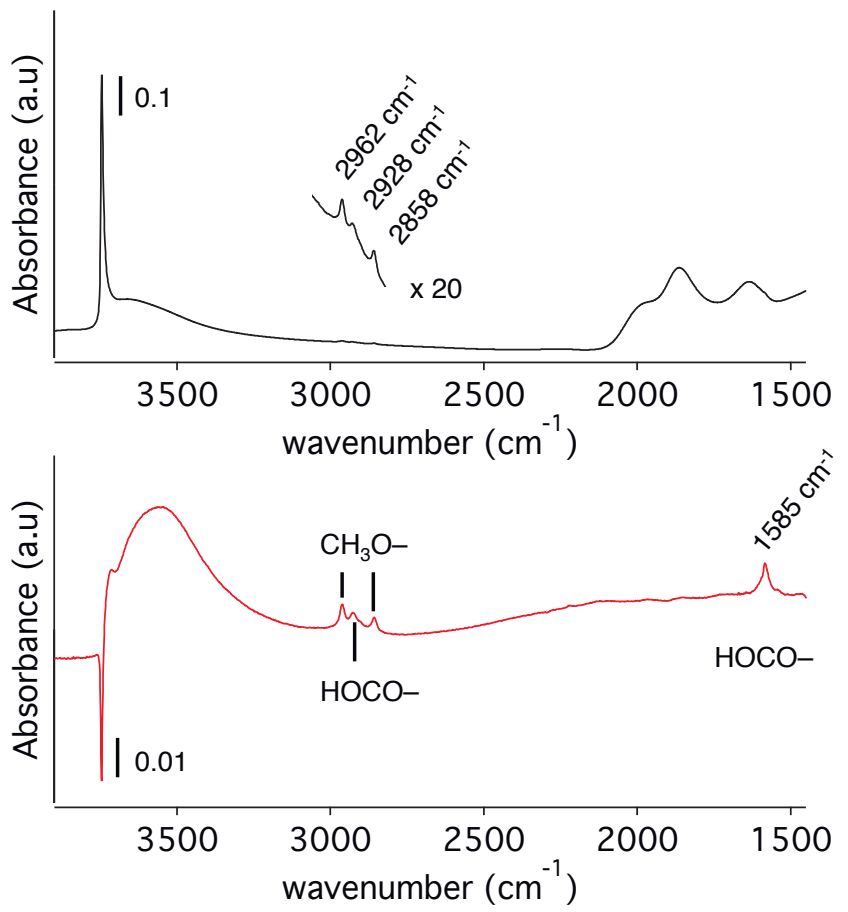

Fig. 3. (top) FTIR of $1_{500} @ \mathrm{SiO}_{2-700}$ after reaction with methane and (bottom) resulting subtracted spectra before and after methane reaction. 
improve the selectivity and increase the amount of active species on the silica surface.

\section{Conclusion}

The SOMC approach was successfully applied to graft monomeric $\mathrm{Cu}$ (II) sites on silica, as confirmed by several spectroscopic techniques. Thermal treatment of the supported metal sites under oxidative condition yields highly dispersed $\mathrm{Cu}$ (II) oxide clusters, according to a combination of EPR, UV-vis and EXAFS analysis. This material is capable of activating methane under mild conditions, leading to the formation of surface methoxy and formate species as determined by infrared spectroscopy. The low methanol yield obtained was rationalised by the formation of small amounts of reactive sites, in contrast to the formation of well-dispersed reactive monomeric $\mathrm{Cu}$ (II) sites on alumina. Further research directions in this field should focus on modifying the direct copper environment to form more reactive sites and employing these findings to increase the metal loading while preserving the selectivity for methanol.

\section{Acknowledgements}

J.M. and M.A.N. would like to acknowledge Dr. Alexander P. van Bavel and Dr. Andrew D. Horton for helpful discussion and Shell Global Solutions International B.V. for financial support. We would like to thank the European Synchrotron Radiation Facility (ESRF), Grenoble, France, for synchrotron resources (beamline BM31; CH 5579) and $\mathrm{H}$. Emerich and D. Stoian for their assistance.

Received: February 14, 2020

[1] J. S. Woertink, P. J. Smeets, M. H. Groothaert, M. A. Vance, B. F. Sels, R. A Schoonheydt, E. I. Solomon, Proc. Natl. Acad. Sci. 2009, 106, 18908, DOI 10.1073/pnas.0910461106.

[2] S. Grundner, M. A. C. Markovits, G. Li, M. Tromp, E. A. Pidko, E. J. M Hensen, A. Jentys, M. Sanchez-Sanchez, J. A. Lercher, Nat. Commun. 2015, 6, 7546, DOI: $10.1038 /$ ncomms8546.

[3] A. J. Knorpp, A. B. Pinar, M. A. Newton, V. L. Sushkevich, J. A. van Bokhoven, Chem CatChem 2018, 10, 5593, DOI: 10.1002/cctc.201801809.
[4] M. Dyballa, D. K. Pappas, K. Kvande, E. Borfecchia, B. Arstad, P. Beato, U. Olsbye, S. Svelle, ACS Catal. 2019, 9, 365, DOI: 10.1021/acscatal.8b04437.

[5] E. M. Alayon, M. Nachtegaal, M. Ranocchiari, J. A. van Bokhoven, Chem. Commun. (Camb). 2012, 48, 404, DOI: 10.1039/c1cc15840f.

[6] M. Ravi, V. L. Sushkevich, A. J. Knorpp, M. A. Newton, D. Palagin, A. B. Pinar, M. Ranocchiari, J. A. van Bokhoven, Nat. Catal. 2019, 2, 485, DOI: 10.1038/s41929-019-0273-z.

[7] K. T. Dinh, M. M. Sullivan, K. Narsimhan, P. Serna, R. J. Meyer, M. Dinc区, Y. Román-Leshkov, J. Am. Chem. Soc. 2019, 141, 11641, DOI: 10.1021/ jacs.9b04906.

[8] T. Ikuno, J. Zheng, A. Vjunov, M. Sanchez-Sanchez, M. A. Ortuño, D. R. Pahls, J. L. Fulton, D. M. Camaioni, Z. Li, D. Ray, B. L. Mehdi, N. D. Browning, O. K. Farha, J. T. Hupp, C. J. Cramer, L. Gagliardi, J. A. Lercher, J. Am. Chem. Soc. 2017, 139, 10294, DOI: 10.1021/jacs.7b02936.

[9] H. V. Le, S. Parishan, A. Sagaltchik, H. Ahi, A. Trunschke, R. Schomäcker, A. Thomas, Chem - A Eur J. 2018, 24, 12592, DOI: 10.1002/chem.201801135.

[10] S. E. Bozbag, P. Sot, M. Nachtegaal, M. Ranocchiari, J. A. van Bokhoven, C. Mesters, ACS Catal. 2018, 8, 5721, DOI: 10.1021/acscatal.8b01021.

[11] C. Copéret, Acc. Chem. Res. 2019, 52, 1697, DOI: 10.1021/acs.accounts.9b00138

[12] C. Copéret, A. Comas-Vives, M. P. Conley, D. P. Estes, A. Fedorov, V. Mougel, H. Nagae, F. Núnez-Zarur, P. A. Zhizhko, Chem. Rev. 2016, 116, 323, DOI: 10.1021/acs.chemrev.5b00373.

[13] C. Copéret, Nat. Energy 2019, 4, 1018, DOI: 10.1038/s41560-019-0491-2.

[14] J. Meyet, K. Searles, M. A. Newton, M. Wörle, A. P. van Bavel, A. D. Horton, J. A. van Bokhoven, C. Copéret, Angew. Chemie Int. Ed. 2019, 58, 9841, DOI: 10.1002/anie.201903802.

[15] K. Zhang, K. F. Lam, B. Albela, T. Xue, L. Khrouz, Q. W. Hou, E. H. Yuan, M. Y. He, L. Bonneviot, Chem. - A Eur. J. 2011, 17, 14258, DOI: 10.1002/ chem.201102026.

[16] G. Martini, L. Burlamacchi, J. Phys. Chem. 1979, 83, 2505, DOI: 10.1021/ j100482a017.

\section{License and Terms}

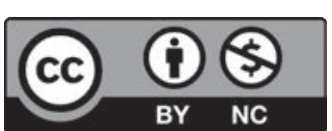

This is an Open Access article under the terms of the Creative Commons Attribution License CC BY_NC 4.0. The material may not be used for commercial purposes.

The license is subject to the CHIMIA terms and conditions: (http:// chimia.ch/component/sppagebuilder/?view=page \&id=12).

The definitive version of this article is the electronic one that can be found at doi:10.2533/chimia.2020.237 